\title{
Análise do custo-benefício da avaliação ocular de pacientes portadores de rosácea
}

\author{
Cost-benefit analysis of ocular examination of patients with rosacea
}

\author{
Keila Barbosa de Oliveira Lima ${ }^{1}$ \\ Luciene Barbosa de Sousa ${ }^{2}$ \\ Namir Clementino Santos ${ }^{3}$ \\ Jeison de Nadai Barros ${ }^{4}$ \\ Denise Antonio ${ }^{5}$
}

Trabalho realizado no Departamento de Oftalmologia da Universidade Federal de São Paulo - UNIFESP.

${ }^{1}$ Médica estagiária do Setor de Doenças Externas Oculares e Córnea da Universidade Federal de São Paulo UNIFESP.

${ }^{2}$ Chefe do Setor de Doenças Externas Oculares e Córnea da Universidade Federal de São Paulo - UNIFESP.

${ }^{3}$ Pós-graduanda, nível doutorado, do Setor de Doenças Externas Oculares e Córnea da Universidade Federal de São Paulo - UNIFESP.

${ }^{4}$ Tecnólogo do laboratório de Doenças Externas Oculares e Córnea da Universidade Federal de São Paulo UNIFESP.

${ }^{5}$ Biomédica do laboratório de Doenças Externas Oculares e Córnea da Universidade Federal de São Paulo UNIFESP.

Endereço para correspondência: Keila Barbosa de Oliveira Lima, Av. Condessa de Vimieiros, 1097 Itanhaém (SP) CEP 11740-000

E-mail: kbol@uol.com.br

Recebido para publicação em 11.02.2004

Versão revisada recebida em 18.10.2004

Aprovação em 22.10.2004

Nota Editorial: Pela análise deste trabalho e por sua anuência na divulgação desta nota, agradecemos aos Drs. Luiz Carlos Molinari e Milton Ruiz Alves.

\begin{tabular}{|l|}
\hline RESUMO \\
\hline Objetivo: Observar as principais manifestações oculares de pacientes porta- \\
dores de rosácea e avaliar o custo-benefício dos exames diagnósticos rea- \\
lizados. Métodos: Vinte pacientes com acne rosácea do Ambulatório de \\
Dermatologia da Universidade Federal de São Paulo (UNIFESP) foram \\
entrevistados por meio de um questionário, submetidos ao exame oftalmoló- \\
gico e aos testes de Schirmer I, fluoresceína, rosa Bengala, citologia de \\
impressão e raspado conjuntival. O levantamento de custos destes exames foi \\
feito a partir da tabela do Sistema Único de Saúde (SUS), medicina de grupo \\
(AMB 90) e valores cobrados no serviço particular. Resultados: De um total \\
de 20pacientes que iniciaramo estudo,16 comparecerama todas as consultas. \\
Houve predomínio do sexo feminino (55\%), raça branca (95\%) e a média de \\
idade foi de 56 anos. Todos os pacientes apresentaram sinais e sintomas \\
clínicos eos principais foram:prurido(40\%),lacrimejamento(35\%), sensação \\
decorpo estranho(30\%),embaçamento visual(25\%), telangiectasiapalpebral \\
(70\%),hiperemiapalpebral(70\%), meibomite(65\%), blefarite(50\%). Osexames \\
subsidiários realizados mostraram-se,em suamaioria, dentro da normalidade. \\
Houve diferença no levantamento de custos das diferentes fontes pagadoras. \\
Conclusões: As principais manifestações oculares de pacientes portadores de \\
rosácea foram sinais e sintomas relacionados com disfunção das glândulas de \\
Meibomius. Considerando os custos dos exames realizados e os resultados \\
obtidos, concluímos que a consulta oftalmológica é a que apresenta melhor \\
custo-benefício para o paciente portador de rosácea.
\end{tabular}

Descritores: Acne rosácea; Testes visuais/economia; Análise custo-benefício; Doenças palpebrais/diagnóstico; Glândulas meibomianas

\section{INTRODUÇ̃̃̃OO}

Rosácea é uma síndrome de etiologia desconhecida que envolve pele e olho. Há predomínio de acometimento em pessoas de pele clara ${ }^{(1)}$. Afeta preferencialmente adultos, podendo ocasionalmente acometer pacientes no final da adolescência; a distribuição de casos em ambos os sexos é similar ${ }^{(2-3)}$.

Vários fatores são associados ao desenvolvimento da doença, tais como: infecção bacteriana, alergia, exposição climática, distúrbios psicossomáticos, desordens gástricas, dieta, ingestão de álcool, disfunção endócrina, anormalidades de glândulas sebáceas, infestação pelo Demodex foliculorum $^{(1)}$, etc.

O envolvimento cutâneo na rosácea caracteriza-se por: eritema, telangiectasia, pápula, pústula e hipertrofia das glândulas sebáceas distribuídas em áreas de rubor que incluem: fronte, nariz, região malar, queixo e o "V" do pescoço ${ }^{(1)}$. Rinofima é um dos mais típicos sinais de acometimento 
cutâneo: caracteriza-se pela hipertrofia das glândulas sebáceas e é geralmente encontrada nos estágios avançados da doença ${ }^{(4)}$.

Arlt (1864) citado por David J (1986) ${ }^{(1)}$, observou e descreveu pela primeira vez a associação entre conjuntivite, ceratite e rosácea.

A prevalência do envolvimento ocular em pacientes com rosácea varia de 3 a $58 \%{ }^{(5)}$. Em pacientes com acometimento ocular e cutâneo, 20\% desenvolvem primeiro as manifestações oculares, 53\% desenvolvem as manifestações cutâneas e 27\%, ambas as manifestações ${ }^{(1)}$.

As manifestações oculares da rosácea variam de leve a severa e envolvem principalmente pálpebra, conjuntiva e córnea. Os sintomas mais comuns são: lacrimejamento, hiperemia e queimação ${ }^{(6)}$. Dentre os sinais clínicos mais freqüentes, destacam-se: blefarite, hiperemia conjuntival, calázio recorrente, ceratite ponteada superficial, proliferação fibrovascular da periferia corneana, infecções palpebrais pelos estafilococos; também conjuntivite nodular (similar à flictênula) ${ }^{(6)}$ e olho seco secundário à disfunção das glândulas de Meibomius ${ }^{(5-6)}$.

As manifestações oculares isoladamente são bastante inespecíficas para garantir diagnóstico de certeza da doença. Para isto é necessário que o envolvimento cutâneo esteja presente. Isto explica porque a rosácea ocular é pouco reconhecida, diagnosticada e tratada. Pelo menos três fatores contribuem para a falha no diagnóstico ${ }^{(1)}$ :

- Primeiro, o oftalmologista freqüentemente falha na inspeção de toda a face do paciente durante seu exame ocular externo.

- Segundo, $20 \%$ dos pacientes com manifestações oculares não específicas de rosácea ainda não desenvolveram lesões de pele.

- Terceiro, a falta de critérios para o oftalmologista fazer o diagnóstico de certeza de rosácea devido à existência de uma constelação de sinais clínicos inespecíficos.

Alguns exames laboratoriais mostraram-se importantes para o diagnóstico precoce do comprometimento ocular. O teste de Schirmer, rosa Bengala e citologia de impressão foram importantes para o diagnóstico de olho seco em pacientes portadores de rosácea ${ }^{(7-9)}$.

O envolvimento ocular na rosácea pode interferir na qualidade de vida dos pacientes, uma vez tratar-se de doença crônica de morbidade considerada. O diagnóstico muitas vezes demanda a realização de vários exames laboratoriais para sua confirmação e o tratamento é prolongado, contribuindo para que haja um impacto econômico, como ausência no trabalho e restrições no tipo de atividade profissional exercida.

O objetivo deste trabalho é observar as principais manifestações oculares de pacientes portadores de rosácea, e avaliar o custo-benefício dos exames realizados.

\section{MÉTODOS}

Durante um período de nove meses, todos os pacientes com diagnóstico de rosácea do Ambulatório de Dermatologia da
UNIFESP foram encaminhados para este estudo que foi realizado no ambulatório de Doenças Externas Oculares e Córnea do Departamento de Oftalmologia da mesma Universidade.

\section{Critérios de Exclusão}

Foram excluídos do estudo:

- Pacientes com idade inferior a 15 anos.

- Pacientes imunodeprimidos.

- Pacientes com outras afecções oculares não relacionadas à rosácea.

- Pacientes que por qualquer motivo, desejaram abandonar o estudo.

- Pacientes grávidas.

Os pacientes incluídos no estudo foram submetidos aos seguintes itens:

1. Questionário sobre a sintomatologia ocular: o paciente primeiro manifestou se havia ou não queixa ocular espontânea e em seguida, foi questionado sobre a presença dos diversos sintomas oculares: ardor, queimação, fotofobia, lacrimejamento, prurido, dor, sensação de corpo estranho, embaçamento visual. A anamnese foi feita por um dos dois médicos examinadores e explicada ao paciente caso houvesse dúvidas sobre os itens questionados.

2. Medida da acuidade visual (com correção ou orifício estenopéico).

3. Biomicroscopia com lâmpada de fenda através de iluminação direta.

4. Tonometria de aplanação com tonômetro de Goldman.

5. Mapeamento de retina com oftalmoscópio indireto.

6. Teste de fluoresceína realizado na lâmpada de fenda, através da instilação de uma gota deste colírio em fundo de saco inferior e após alguns minutos feita a análise da superfície corneana (ceratite ponteada) através da luz de cobalto (iluminação azul da lâmpada de fenda). A ceratite foi classificada pela localização em superior, inferior, difusa ou em fenda palpebral.

7. Teste de rosa Bengala realizado na lâmpada de fenda; uma gota deste colírio foi instilada em cada um dos olhos e observada a coloração da superfície ocular; foi usada a escala de Van Bijsterveld em que os valores da coloração foram baseados em graus de 0-3 em cada uma das 3 áreas: conjuntiva bulbar nasal exposta, conjuntiva bulbar temporal exposta e córnea, num total de 9.

8. Teste de Schirmer ${ }^{(4)}$ : o paciente manteve seus olhos abertos e um filtro de papel milimetrado foi inserido em fundo de saco inferior de cada um dos olhos, mantido por 5 minutos, após o qual foi avaliado o valor da escala do papel que ficou molhado pela lágrima. É considerado teste quantitativo da camada aquosa da lágrima.

9. Citologia de impressão da conjuntiva bulbar inferior ${ }^{(10-12)}$. O teste foi feito usando uma fita de acetato de celulose sendo comprimida na região da conjuntiva bulbar inferior por um período de 10 segundos, sendo logo após fixada em uma mistura de ácido acético glacial, formaldeído a 37\% e álcool etílico a 70\% na proporção 1:1:20 e posteriormente corado 
com protocolo que envolve as colorações PAS (Periodic Acid Schiff), hematoxilina e Papanicolaou modificados, conforme técnica previamente descrita ${ }^{(12)}$. Avalia os seguintes achados microscópicos: presença de células caliciformes, "imprints" de mucina, presença de polimorfonucleares, relação núcleo citoplasmática do epitélio. Foi usada a escala de Nelson para a classificação do exame (grau 0-3) ${ }^{(12)}$, na qual os graus 0 e 1 são considerados normais.

10. Raspado conjuntival para estudo da flora microbiana da superfície ocular (bacterioscopia pela coloração de Gram, citologia pela coloração de Giemsa e cultura em meios de Ágar sangue e Ágar chocolate).

O estudo foi realizado por 2 médicos examinadores (itens 1 a 8) e por 2 técnicos do laboratório do mesmo Departamento, um responsável pelo item 9 e o outro pelo item 10 .

Os pacientes foram examinados por um dos dois médicos em cinco consultas diferentes (uma por semana), uma vez que os testes usados poderiam sofrer influências dos diferentes corantes se realizados no mesmo dia; na primeira consulta foram aplicados os itens de 1 a 6 . Os pacientes não tiveram nenhum custo com os exames, bem como não receberam nenhum pagamento ou ajuda financeira durante o estudo.

Os custos de cada procedimento foram determinados pelos valores pagos pelo SUS (Sistema Único de Saúde), grupos de saúde (Tabela AMB 90 no valor da $\mathrm{CH}$ de 0,25 reais) e custos particulares levantados no Instituto Paulista de Ensino e Pesquisa em Oftalmologia (IPEPO). Estes valores foram comparados entre si.

O trabalho foi submetido ao Comitê de Ética Médica da UNIFESP.

Para a comparação entre as opções presente e ausente relativo aos sintomas, achados na pálpebra, conjuntiva, córnea, citologia e cultura, utilizou-se o teste estatístico qui-quadrado para as diferenças de proporção (presente e ausente). Para comparação entre as opções nos exames fluoresceína, rosa Bengala, Schirmer e citologia de impressão, utilizou-se o teste qui-quadrado para associação e medidas, considerando a junção de olho direito e olho esquerdo. O pacote estatístico SPSS 11.5 for Windows (SPSS Inc.) foi utilizado para isso. O nível de significância estatística foi aceito em $\alpha \leq 0,05$.

\section{RESULTADOS}

Foram examinados 20 pacientes, sendo 9 do sexo masculino $(45 \%)$ e 11 do sexo feminino $(55 \%)$.

A faixa etária encontrada foi de 26 a 82 anos, com média de 54 anos. O intervalo mais frequiente foi entre 41 e 50 anos $(35 \%)$. Apenas um paciente apresentou idade inferior a 30 anos (26 anos).

Deste total de 20 pacientes, $19(95 \%)$ eram da raça branca e apenas um paciente da raça amarela.

Com relação às queixas oculares, apenas 2 pacientes tiveram queixa unilateral. Quinze pacientes dos 20 avaliados (75\%), apresentaram queixas oculares espontâneas; todos os pacientes assintomáticos apresentaram algum tipo de queixa quando questionados a respeito dos sintomas. As queixas oculares foram: prurido $(40 \%, \mathrm{p}=0,37)$, lacrimejamento $(35 \%$, $\mathrm{p}=0,18)$, sensação de corpo estranho $(30 \%, \mathrm{p}=0,074)$, ardor ( $25 \%, \mathrm{p}=0,025)$, embaçamento visual $(25 \%, \mathrm{p}=0,025)$, dor $(15 \%$, $\mathrm{p}=0,002)$, irritação $(5 \%, \mathrm{p}=0,000)$ e hiperemia $(5 \%, \mathrm{p}=0,000)$.

Ao analisarmos a acuidade visual (AV), 16 dos 40 olhos examinados $(40 \%)$ apresentaram AV menor que 0,7 . As causas encontradas que justificam esta baixa de acuidade visual (BAV) estão descritas no gráfico demonstrativo (Figura 1).

Os pacientes que tiveram BAV por alterações corneanas apresentaram opacidade e vascularização; já os que tiveram alterações retinianas apresentaram degenerações associadas à alta miopia. Não foi possível determinar a causa de BAV em $50 \%$ dos olhos.

Os principais achados oculares biomicroscópicos foram alterações nas pálpebras, conjuntiva e córnea (Quadro 1). Outros sinais menos freqüentes foram: blefarite $(50 \%, \mathrm{p}=1,00)$, edema palpebral $(15 \%, \mathrm{p}=0,002)$, calázio $(15 \%, \mathrm{p}=0,002)$, hordéolo $(10 \%, \mathrm{p}=0,000)$, distiquíase, poliose, lagoftalmo $(5 \%$, $\mathrm{p}=0,000)$; pinguécula $(20 \%, \mathrm{p}=0,007)$, pterígio $(15 \%, \mathrm{p}=0,002)$,

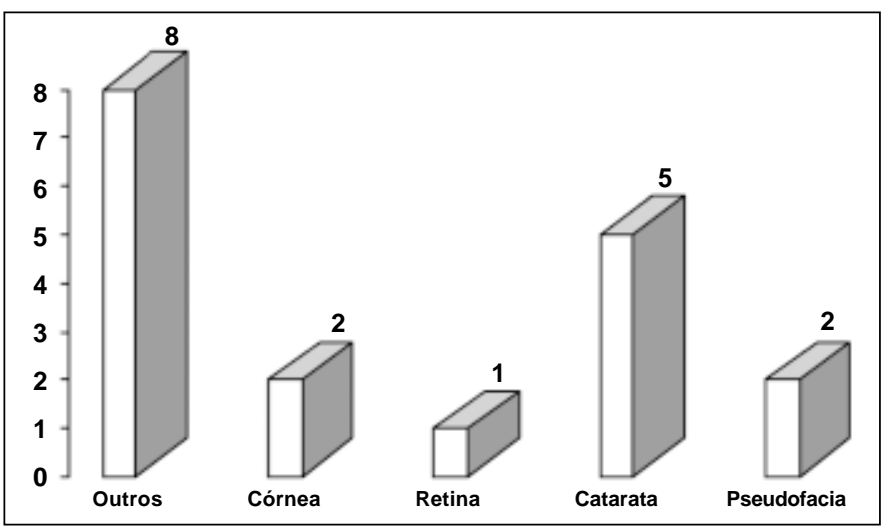

Figura 1 - Gráfico demonstrativo da distribuição das causas de baixa acuidade visual da população estudada em pacientes com rosácea, UNIFESP - 2003

\begin{tabular}{|c|c|c|}
\hline \multicolumn{3}{|c|}{$\begin{array}{l}\text { Quadro } 1 \text { - Principais achados oculares em pacientes com rosácea, } \\
\text { UNIFESP - } 2003\end{array}$} \\
\hline Sinais & \multicolumn{2}{|c|}{ № de olhos (\%) } \\
\hline \multicolumn{3}{|l|}{ Pálpebras } \\
\hline Telangiectasia & $28(70)$ & $(p=0,074)$ \\
\hline Hiperemia & $28(70)$ & $(p=0,074)$ \\
\hline Meibomite & $26(65)$ & $(p=0,180)$ \\
\hline \multicolumn{3}{|l|}{ Conjuntiva } \\
\hline Hiperemia & $22(55)$ & $(p=0,655)$ \\
\hline Pinguécula & $8(20)$ & $(p=0,007)$ \\
\hline Fibrose & $8(20)$ & $(p=0,007)$ \\
\hline \multicolumn{3}{|l|}{ Córnea } \\
\hline Opacidade periférica & $10(25)$ & $(p=0,025)$ \\
\hline Vascularização & $8(20)$ & $(p=0,007)$ \\
\hline Pannus & $8(20)$ & $(p=0,007)$ \\
\hline
\end{tabular}


papilas, folículos, concreções calcárias e nódulos conjuntivais $(5 \%, \mathrm{p}=0,000)$. Afinamento $(15 \%, \mathrm{p}=0,002)$, ceratite ponteada $(15 \%, \mathrm{p}=0,002)$, depósito lipídico $(10 \%, \mathrm{p}=0,000)$ e edema $(5 \%, \mathrm{p}=0,000)$ foram sinais menos comumente encontrados na córnea.

Sinéquia anterior foi encontrada em um olho (2,5\%). Em nenhum dos olhos foram observadas alterações de câmara anterior (células ou "flare"), sinais de esclerite, episclerite e vitreíte.

Opacidade de cristalino foi observada em 5 olhos $(12,5 \%)$ e pseudofacia em 2 olhos (5\%).

Os valores de pressão intra-ocular mantiveram-se entre 8 e $17 \mathrm{mmHg}$, similares em ambos os olhos, em todos os pacientes.

No exame de mapeamento de retina, a maioria apresentouse normal; um paciente apresentou fundo miópico. Em um dos olhos foi impossível a realização do exame devido à opacidade corneana total.

Ao teste de fluoresceína, a maioria dos olhos $(90 \%$, $\mathrm{p} \leq 0,001)$ não corou. Houve coloração com padrão de ceratite ponteada difusa em 2 olhos $(5 \%)$ e ceratite ponteada inferior em 2 olhos (5\%).

$\mathrm{Na}$ coloração com colírio de rosa Bengala 1\%, 18 olhos $(45 \%, \mathrm{p}=0,001)$ não coraram, 7 olhos $(17,5 \%)$ coraram GI e 3 olhos (7,5\%) GII, 4 olhos (10\%) coraram GIII, um olho $(2,5 \%)$ corou GIV e 3 olhos (7,5\%) coraram G VI. Dois pacientes não fizeram este exame.

$\mathrm{Na}$ avaliação com o teste de Schirmer I os seguintes resultados foram obtidos: menor de $5 \mathrm{~mm}$ em nenhum olho; entre 5 $10 \mathrm{~mm}$ em 4 olhos (10\%) e maior que $10 \mathrm{~mm}$ nos demais olhos $(75 \%, \mathrm{p} \leq 0,001)$. Três pacientes não fizeram este exame.

Os resultados da classificação da citologia de impressão, segundo a escala de Nelson ${ }^{(18)}: 26$ olhos $(65 \%, \mathrm{p}=0,002)$ foram normais (G0 e GI), 8 olhos (20\%) alterados (GII e GIII). Três pacientes não fizeram este exame.

$\mathrm{Na}$ investigação laboratorial encontramos à bacterioscopia a presença de cocos Gram positivo em 12 pacientes $(60 \%$, $\mathrm{p}=001)$; bacilos e cocos Gram positivo em 2 pacientes $(10 \%)$ e somente bacilos Gram positivo em um paciente (5\%). Três pacientes apresentaram resultado negativo (15\%) e 2 pacientes não realizaram este exame.
Os resultados obtidos à citologia sob a coloração de Giemsa foram: presença de neutrófilos, mononucleares e muco em 12 pacientes $(60 \%)$; somente neutrófilos e mononucleares em 2 pacientes (10\%); neutrófilos e muco em 2 pacientes (10\%); neutrófilos, mononucleares, muco e células caliciformes em um paciente (5\%); células em degeneração e degeneradas em um paciente $(5 \%)$. A presença de neutrófilos, mononucleares e muco apresentou significância estatística $(\mathrm{p}=0,000$; $\mathrm{p}=0,002 ; \mathrm{p}=0,005$ respectivamente). Dois pacientes não realizaram este exame.

Houve crescimento dos seguintes patógenos no exame de cultura: Staphylococcus coagulase negativo em 9 pacientes (50\%, $\mathrm{p}=1,000) ;$ Corynebacterium xerosis em 4 pacientes (22,2\%, p=0,018); Staphylococcus aureus em 3 pacientes $(16,7 \%, \mathrm{p}=0,005)$; bacilo coagulase negativo em um paciente $(5,6 \%, \mathrm{p}=0,000)$; não houve crescimento de patógeno em 2 pacientes $(11,1 \%, \mathrm{p}=0,001)$. Dois pacientes não realizaram este exame. Alguns pacientes apresentaram mais do que um patógeno na cultura.

Os preços de cada exame de acordo com a tabela SUS, medicina de grupo e particular foram pesquisados e estão correlacionados abaixo no quadro 2.

Quatro pacientes não fizeram todos os exames, porém não foram excluídos do trabalho.

\section{DISCUSS $\tilde{A} O$}

Rosácea é uma doença classicamente descrita como dermatológica, que pode ou não apresentar comprometimento ocular. rosácea sem envolvimento ocular acomete de duas a três vezes mais mulheres do que homens ${ }^{(8,13-14)}$; em casos de manifestações oculares, esta proporção se equivale ${ }^{(3)}$, mostrando apenas um predomínio discreto de acometimento no sexo feminino ${ }^{(1)}$. Neste estudo houve um predomínio do sexo feminino $(55 \%)$.

Segundo dados da literatura dermatológica ${ }^{(6)}$, os pacientes com rosácea encontram-se principalmente na faixa etária entre 41 a 50 anos, mesmo intervalo em que a maioria dos pacientes

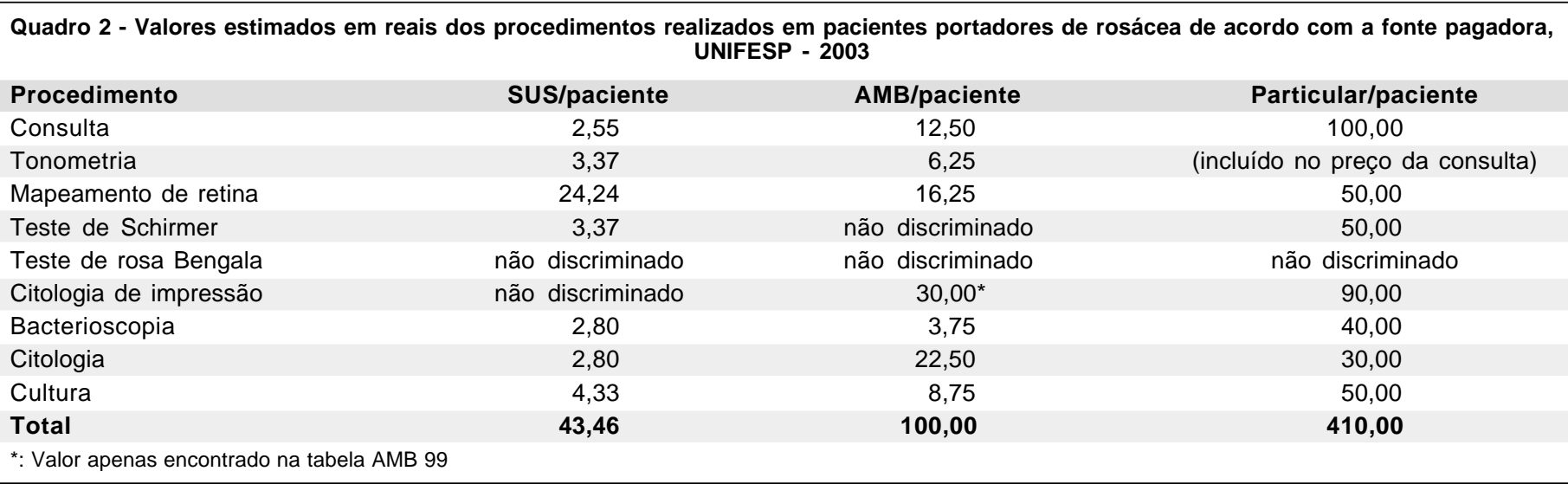


deste estudo foram encontrados, sendo a faixa etária média de 54 anos e apenas 1 paciente apresentou idade inferior a 30 anos (26 anos).

Quanto à raça, este estudo corrobora os achados da literatura, que mostra um consenso de maior prevalência de rosácea em pessoas de pele clara descendentes do nordeste Europeu ${ }^{(3,14)}$.

Houve queixa ocular espontânea em $75 \%$ dos pacientes encaminhados, queixas estas inespecíficas, porém compatíveis com o quadro clínico de rosácea: prurido, lacrimejamento, sensação de corpo estranho, ardor, embaçamento visual. Quarteman et al. encontraram em uma amostra de 33 pacientes os mesmos sintomas ${ }^{(13)}$. Observou-se em nosso estudo que todos os pacientes, quando interrogados a respeito de sintomas oculares, apresentavam queixas. Num estudo de 39 pacientes com rosácea cutânea, todos apresentaram sinal de doença ocular ${ }^{(13)}$. A presença de nenhum dos sintomas encontrados apresentou significância estatística e sim a ausência de alguns deles como queimação, irritação, hiperemia, dor, ardor e embaçamento visual.

A acuidade visual (AV) em $40 \%$ dos pacientes deste estudo foi menor que 0,7 ; as principais causas de $\mathrm{BAV}$ não se relacionam com complicações de rosácea. Os pacientes não foram submetidos ao exame de refração, portanto, vício refrativo pode ser a principal causa de BAV. O comprometimento corneano pode levar o paciente a perdas mais severas da AV em casos de rosácea ${ }^{(6)}$, porém neste estudo, esta não foi a principal causa de BAV.

Achados biomicroscópicos principais em pacientes com rosácea demonstrados na literatura ${ }^{(3)}$ são: telangiectasia, disfunção de glândula de Meibomius; neste estudo encontrouse: telangiectasia palpebral (70\%), hiperemia $(70 \%)$, meibomite $(65 \%)$ e blefarite (50\%). Não houve significância estatística para nenhum dos principais sinais encontrados, embora os achados sejam compatíveis com os da literatura. O diagnóstico de meibomite foi feito pela presença da dilatação dos orifícios das glândulas de Meibomius com estase de seu conteúdo. O diagnóstico de blefarite foi dado pela presença de crostas na base dos cílios.

O envolvimento conjuntival mais encontrado neste estudo foi hiperemia da conjuntiva bulbar (50\%), pinguécula (20\%) e fibrose conjuntival (20\%). Akpek et al. encontraram hiperemia conjuntival como achado mais freqüente (45\%) e conjuntivite cicatricial em 9\%, numa amostra de 131 pacientes $^{(3)}$. rosácea é considerada uma das causas de conjuntivite cicatricial e também incluída no diagnóstico diferencial de granuloma de conjuntiva ${ }^{(15)}$. No presente estudo foi observado nódulo conjuntival em 2 olhos (5\%). O achado conjuntival mais encontrado neste exame é compatível com a literatura, embora não haja significância estatística para o mesmo. Outra causa importante de fibrose conjuntival no Brasil é o tracoma cicatricial, porém não foi diagnosticado em nosso estudo.

O envolvimento corneano é sem dúvida o problema alvo na rosácea ocular e tem sido descrito em variáveis graus ${ }^{(3)}$. Tem prognóstico desfavorável e pode levar à perda de vi- são ${ }^{(3,6)}$. No grupo estudado, foi encontrado opacidade periférica em arco (25\%), pannus (20\%), neovascularização (20\%), afinamento estromal (15\%) e ceratite ponteada inferior $(15 \%)$. Opacidade periférica em arco, considerada degeneração corneana tem relação com a idade ${ }^{(4)}$ e não é encontrada na literatura em associação com rosácea, diferentemente de pannus, considerado ter como uma de suas principais causas a rosácea ${ }^{(4)}$.

Ao teste de fluoresceína, 2 olhos (5\%) apresentaram ceratite ponteada difusa e 3 olhos $(7,5 \%)$ apresentaram ceratite ponteada inferior. O resultado negativo deste exame (não cora) teve significância estatística, resultado este que difere da literatura, a qual considera ceratite ponteada um dos achados corneanos mais comuns ${ }^{(3)}$.

Em um estudo comparativo entre pacientes com rosácea, síndrome de Sjöegren e grupo controle, encontrou-se ${ }^{(10)}$ um maior número de pacientes portadores de rosácea corando com teste de rosa Bengala do que nos outros grupos; neste mesmo estudo, não houve correlação entre o teste de rosa Bengala e sinais patológicos das glândulas de Meibomius. No presente estudo, apenas 2 pacientes $(5 \%)$ apresentaram ao teste de rosa Bengala uma classificação grau VI, porém todos apresentaram patologia das glândulas de Meibomius, embora o comprometimento glandular não tenha sido classificado para tal correlação. O resultado negativo deste exame (não cora) apresentou significância estatística, podendo ser considerado dispensável para o diagnóstico de rosácea.

Quanto ao valor do teste de Schirmer este é considerado normal entre $10-30 \mathrm{~mm}$ no final de 5 minutos. Esta quantidade diminui com a idade, mas provavelmente não deverá ser menor do que $10 \mathrm{~mm}^{(4)}$. Na literatura, encontramos alguns estudos apresentando teste de Schirmer normal em pacientes com rosácea ${ }^{(13,16-17)}$; também encontramos estudo ${ }^{(5)}$ com valores de Schirmer I mais baixos em pacientes com rosácea ocular comparados com o grupo controle. Os pacientes deste estudo apresentaram testes com valores normais em $75 \%$ dos olhos, com significância estatística.

A citologia de impressão tem sido usada para estudo histológico da superfície ocular, avaliando características das células epiteliais superficiais, densidade das células caliciformes, presença de mucina, presença de células inflamatórias e graduação do estágio da metaplasia escamosa. Neste estudo, 26 olhos (65\%) apresentaram grau 0 e 1, compatíveis com a normalidade de acordo com a classificação de Nelson ${ }^{(11)} \mathrm{com}$ significância estatística. Estes dados corroboram os achados na literatura ${ }^{(18)}$.

A presença de cocos Gram positivo teve valor estatisticamente significante, mas pode ser considerado componente da flora normal da pálpebra ${ }^{(4)}$. A presença de neutrófilos, mononucleares e muco, apesar da significância estatística, representa sinal inespecífico e necessita ser analisado juntamente com os demais sinais clínicos.

Staphylococcus não aureus podem ser isolados em 9095\% das pálpebras normais e Staphylococcus aureus em 10- 
$35 \%{ }^{(4)}$. Staphylococcus não aureus e Propionibacterium acnes são freqüentemente isolados na maioria das pálpebras, principalmente em pacientes sem blefarite ${ }^{(4)}$. Também neste estudo, os patógenos mais freqüentes foram Staphylococcus coagulase - negativo e Corynebacterium xerosis, sem significância estatística.

A análise dos custos diretos de cada exame realizado mostrou diferenças nas fontes pagadoras: em relação à tabela SUS, o valor da tabela AMB 90 apresentou-se 2,5 vezes maior, enquanto que o valor do custo particular foi aproximadamente 10 vezes maior. Os custos diretos não médicos (gastos com meio de transporte, suporte, e outras despesas relacionadas), custos indiretos (horas de trabalho perdidas) e custos intangíveis (desconforto decorrente do exame) não foram calculados, o que poderia contribuir para um maior impacto socioeconômico ao paciente. A relação custo-benefício de cada exame realizado não é favorável, pois nenhum dos exames mostrou ter relevância clínica para o diagnóstico de rosácea ocular.

Cem por cento dos pacientes apresentaram alterações ao exame oftalmológico, independentemente de apresentarem ou não queixa espontânea. Ao serem questionados, todos apresentaram algum sintoma, fato que pode ser explicado pelos achados clínicos. O presente estudo sugere que a consulta oftalmológica foi soberana para o diagnóstico de rosácea ocular, sendo uma conduta recomendada aos pacientes com diagnóstico dermatológico de rosácea.

O número pequeno da amostra deste estudo pode ser justificado pelo baixo número de pacientes com diagnóstico de rosácea, pacientes estes drenados de um Serviço dermatológico considerado terciário, num intervalo de 9 meses. Tal número pode ter contribuído para os resultados obtidos na análise estatística. Estudos futuros com uma amostra maior de pacientes poderão contribuir para a comparação com os resultados encontrados.

\section{CONCLUSÃO}

As principais manifestações oculares dos pacientes portadores de rosácea foram sinais e sintomas relacionados com disfunção das glândulas de Meibomius.

Considerando os custos e os resultados dos exames realizados, concluiu-se que a consulta oftalmológica é a que apresenta a melhor relação custo-benefício ao paciente com rosácea.

\section{AGRADECIMENTOS}

Agradecemos a intensa colaboração das funcionárias Cleide e Sebastiana, do Setor de Doenças Externas Oculares e Córnea da UNIFESP.

Agradecemos a dedicação de Carla Luguetti, responsável pela análise estatística do trabalho.

\section{ABSTRACT}

Purpose: To observe the main ocular manifestations of patients with rosacea and to evaluate the cost-benefit of supplementary diagnostic examinations. Methods: Twenty patients with acne rosacea from the Dermatology Service of the São Paulo Federal University (UNIFESP) were interviewed through a questionnaire, submitted to ophthalmologic examination and tested with Schirmer I, fluorescein and rose Bengal staining, impression cytology and conjunctival scrub. The costs of these examinations were abstracted from the Public Health System's values (SUS), Brazilian Medical Association values (AMB) and values charged by a private service. Results: Twenty patients were enrollet initially in the study, but only 16 completed it. Eleven patients were female (55\%), 19 were white (95\%) and the average age was 56 years. All patients had at least one complaint related to rosacea. The most common symptoms were itching $(40 \%)$, tearing (35\%), foreign body sensation $(30 \%)$. The most common signs were telangiectasis of lid margins (70\%), hyperemia of lid margins (70\%), meibomitis (65\%) and blepharitis (50\%). Most subsidiary examination showed normal results. There was difference of costs between the different paying sources. Conclusions: The main ocular manifestations in rosacea were related with meibomian gland disease. Considering the subsidiary examination costs and their results, the ophthalmologic check-up presents the best cost-benefit for the patient with rosacea.

Keywords: Acne rosacea; Vision tests/economics; Cost-benefit analysis; Eyelid diseases/diagnosis; Meibomian glands

\section{REFERÊNCIAS}

1. Browning DJ, Proia AD. Ocular rosacea. Surv Ophthalmol. 1986;31(3):14558. Review.

2. Marks R. Concepts in the pathogenesis of rosacea. Br J Dermatol. 1968;80 (3): $170-7$

3. Akpek EK, Merchant A, Pinar V, Foster CS. Ocular rosacea: patient characteristics and follow-up. Ophthalmology. 1997;104(11):1863-7.

4. Arffa RC. Grayson's diseases of the cornea. 4th ed. St Louis: Mosby; 1997.

5. Zengin N, Tol H, Gündüz K, Okudan S, Balevi S, Endogru H. Meibomian gland dysfunction and tear film abnormalities in rosacea. Cornea. 1995;14(2):144-6.

6. Tanzi EL, Weiberg JM. The ocular manifestations of rosacea. Cutis. 2001;68 (2):112-4. Review.

7. Zug KA, Palay DA, Rock B. Dermatologic diagnosis and treatment of itchy red eyelids. Surv Ophthalmol. 1996;40(4):293-306. Review.

8. Kligman AM. Ocular rosacea. Current concepts and therapy. Arch Dermatol. 1997;133(1):89-90.

9. Gudmundsen KJ, O’Donnell BF, Powell FC. Schirmer testing for dry eyes in patients with rosacea. J Am Acad Dermatol. 1992;26(2 Pt 1):211-4.

10. Pflugfelder SC, Tseng SC, Yoshino K, Monroy D, Felix C, Reis BL. Correlation of goblet cell density and mucosal ephitelial membrane mucin expression with rose bengal staining in patients with ocular irritation. Ophthalmology. 1997;104(2):223-35.

11. Nelson JD. Cellulose acetate impressions of the ocular surface. Dry eyes states. Arch Ophthalmol. 1983;101(12):1869-72.

12. Barros JN, Mascaro VLDM, Gomes JAP, Freitas D, Lima ALH. Citologia de impressão de superfície ocular: técnica de exame e de coloração. Arq Bras Oftalmol. 2001; 64(2):127-31. 
13. Quarterman MJ, Johnson DW, Abele DC, Lesher JL Jr, Hull DS, Davis LS. Ocular rosacea. Signs, symptoms, and tear studies before and after treatment with doxycycline. Arch Dermatol. 1997;133(1):49-54.

14. Berg M, Lidén S. An epidemiological study of rosacea. Acta Derm Venereol. 1989;69(5):419-23.

15. Hoang-Xuan T, Rodriguez A, Zaltas MM, Rice BA, Foster CS. Ocular rosacea. A histologic and immunopathologic study. Ophthalmology. 1990;97(11):1468-75.

16. Macri A, Pflugfelder S. Correlation of the Schirmer 1 and fluorescein clearance test with the severity of corneal epithelial and eyelid disease. Arch Ophthalmol. 2000;118(12):1632-8.

17. Hope-Ross MW, Chell PB, Kervick GN, McDonnell PJ. Recurrent corneal erosion: clinical features. Eye. 1994;8(Pt 4):373-7.

18. Pflugfelder SC, Tseng SC, Sanabria O, Kell H, Garcia CG, Felix C, et al. Evaluation of subjective assessments and objective diagnostic tests for diagnosing tear-film disorders known to cause ocular irritation. Cornea. 1998;17(1): $38-56$.

\section{Congresso Internacional de Oftalmologia XXVI Congresso Pan-Americano de Oftalmologia XVII Congresso Brasileiro de Prevenção da Cegueira e Reabilitação Visual}

\section{0 a 24 de fevereiro de 2006}

Transamérica Expo-Center SÃO PAULO - SP

IN FORMAÇÕES: Meeting Eventos

Fone: (11) 3849-8263 - Fax: (11) 3849-0379

E-mail: info@ophthalmology2006.com.br

Home-page: www.ophthalmology2006.com.br 